\title{
28 Research Square \\ Social support for women after fistula repair: a scoping review
}

Kondwani Wella ( $\sim$ kwella@kcn.unima.mw)

University of Malawi Kamuzu College of Nursing https://orcid.org/0000-0001-7506-7777

Evelyn Chilemba

University of Malawi Kamuzu College of Nursing

Annie Namathanga

University of Malawi Kamuzu College of Nursing

\section{Bertha Chakhame}

University of Malawi Kamuzu College of Nursing

\section{Research article}

Keywords: Obstetric fistula, Social support, social networks, Berkman's model

Posted Date: August 12th, 2019

DOI: https://doi.org/10.21203/rs.2.12609/v1

License: (c) (1) This work is licensed under a Creative Commons Attribution 4.0 International License.

Read Full License

Version of Record: A version of this preprint was published at Sexual \& Reproductive Healthcare on July 1st, 2021. See the published version at https://doi.org/10.1016/j.srhc.2021.100649. 


\section{Abstract}

Background Obstetric fistula (OF) is a birth complication that largely affects women in developing countries. The women suffer constant incontinence, shame, social segregation, and health problems. Reconstructive surgery can usually repair $\mathrm{OF}$, and enable women to reintegrate back into their communities. However, physically repair does not necessarily result in emotional recovery. Our objective was to explore women's experiences of social support during the twelve months following a first time OF repair. Methods An evidence synthesis was performed based on a systematic search of literature published between 2008 and October 2019 in PubMed, Medline and CINAHL databases using keywords "Obstetric Fistula", "vesicovaginal fistula", "vesicovaginal", "Fistula", and "Social Support". Inclusion criteria were primary peer reviewed articles addressing one or more study objectives, in English, on OF support, regardless of location. Two reviewers independently assessed eligibility of the studies and extracted the data. Disagreement between the reviewers were resolved by a third reviewer. Results The search resulted in 212 articles, of which 15 were included in this review. The analysis of the studies was guided by Berkman's Model. The model suggests that there is a link between social resources, social support and disease. We found that support was either internal or external. Internal support constituted self-efficacy resulting into strengthened internal locus of control. Externally, women were supported by friends and family with material and financial resources. They were also supported with education opportunities, and business start-up capital. Our review also identified the need to support women with information about OF. Most women who were successfully integrated into their communities supported other women suffering from OF. Conclusions Social networks make a significant contribution to emotional and psychological recovery of women after a successful OF surgical repair. Social networks were also found to be detrimental to emotional and psychological recovery of women. Most women were abandoned and not supported by their husbands. Only constructive surgery is not enough as OF treatment. Women need supportive and well organised social networks for them to make full recovery after OF repair.

\section{Background}

Obstetric Fistula (OF) is a birth complication most often resulting from prolonged, obstructed labour which creates an opening between the vagina and rectum and/or the vagina and bladder. It is a life changing condition that disproportionately affects vulnerable women, especially in low and middle income countries [1]. The World Health Organisation estimates that each year between 50,000 to 100,000 women are affected [2]. Tunçalp, Tripathi, Landry, Stanton and Ahmed [3] argue that the high incidence of $\mathrm{OF}$ is an indicator of failure of health systems in developing countries to deliver timely, accessible, and appropriate intrapartum care.

Kalirani-Phiri, Umar, Lazaro, Lunguzi and Chilungo [4] estimate the prevalence of OF in Malawi at 1.6 per 1000 women. OF is preventable, treatable, and has been eliminated in industrialized countries through the availability of timely, high-quality medical interventions for prolonged and obstructed labour [5]. Fistula repair in Malawi has brought some hope to women who have suffered from the condition. There 
is an increasing number of women coming for fistula repair from the rural areas of Malawi. To improve quality of life in the post-repair period it is also imperative to identify the barriers to psychosocial support, which is essential to resumption of normal life. To effectively support women in the post repair period there is need to potentially develop a model for support or alternatively to create guidelines on the support of these clients for the first year post-repair. Psychosocial support is essential in health illness continuum because it has a buffering effect on the individuals, thereby enhancing healthy adjustments to life [6]. The increasing number of women undergoing OF repair Indicates women's desire for quality of life. Psychosocial support is most effective when individuals involved interact and respond to each other in a social climate of mutuality and reciprocal relationship [7].

Health care workers are advocates for psychosocial support and identify the opportunities for implementation of such support. Psychosocial support lead to a sense of wellbeing and self-worth in women, yet little is known about how these women have reintegrated back in their families and communities after successful fistula repair. Social support includes interpersonal dimension in which one of the individuals in the relationship becomes an advocate for the other, thus the relationship is communal within a specific context [7]. After successful OF repair there is need to promote women's quality of life through social support as it potentiates consequences which are health related and results in the psychological wellbeing [8]. There is need to instil recognition of self-worth, life satisfaction, healthy coping skills and a sense of stability among these women. According to Khan and Antonucci [9] establishing positive support among those affected by life events is best responded to by small networks compared to large networks. It is not known in Malawian settings as to what could be the ideal support system in successful fistula repairs to promote quality of life. Therefore, this scoping review is conducted with the aim of identifying the key issues associated with social support following a successful fistula repair.

Purpose

To explore women's experiences of social support during the twelve months following a first time OF repair.

\section{Objectives}

1. To holistically assess women's experiences of social support (i.e., psychological, social, sexual)

2. To describe the women's social networks pre- and post-fistula repair

3. To examine the nature and effectiveness of social support networks including but not limited to spousal/partner relationships

Review questions

The scoping review was guided by the following questions: 
1. What are the women's social support experiences during the twelve months following a first time OF repair?

2. What are the existing social support networks available for women pre and post-OF repair? (What social support networks exist or would be desired for women pre- and post-OF repair?)

3. How effective are the women's existing social support networks post-OF repair? At the spousal/partner level? At the family level? At the community level?

\section{Methods}

For the scoping review to be reproducible, transparent and consistent a protocol was developed as a framework to guide the process. The protocol included a list of definitions, search algorithms and abstract screening form. The review team comprised a multidisciplinary team of experts in library science, nurse educators and nurse practitioner.

Sources and Search/Type of Sources

The studies for the scoping review were sourced from PubMed, Medline, and CINAHL. The sources included published primary research articles, from qualitative or quantitative studies that were peer reviewed and addressed issues of family/community support post OF repair. Only articles written in English and published between 2007 and 2019 were selected. There was no limitation on location of study. A complete scoping review protocol is provided in the index.

\section{Search Strategy}

In order to ensure a comprehensive search, literature search was done using the following data bases; PubMed, Medline, and CINAHL. The search strategy used the Boolean operator 'AND'. Search terms such as: obstetric fistula repair, experiences, post-operative and support were used. The search queries used were: obstetric fistula repair AND postoperative, obstetric fistula repair AND experiences, obstetric fistula repair AND support. The search terms were entered as the first set of key words. Additional articles were identified using reference lists of the selected published journal articles. Following the search 212 articles were identified. Screening was done to remove irrelevant articles and duplicates. Fifteen relevant research articles were identified and reviewed, summarised, and synthesised in Table 1. Additional grey literature with primary information was identified and considered in the scoping review. WHO and UNFPA websites yielded additional grey literature.

Relevance Screening and Inclusion Criteria

Articles were identified based on the inclusion and exclusion a priori criteria. A screening form was developed to aid in reviewing the abstracts and the titles. Primary peer reviewed articles were considered relevant if they addressed one or more study objectives, were in English, on OF support, regardless of location, published between 2007 and 2019 and were primary research articles. The exclusion criteria comprised all articles in other languages, duplicate articles, review papers, papers on other types of 
fistula, non-free articles, commentary and opinion papers. A 12 year period was chosen in order to have recent information which is relevant and related to the topic under study.

Selection of Studies for Inclusion

Two reviewers independently scanned all abstracts and determined on relevance to the review. All abstracts that were considered potentially relevant by either reviewer were reviewed in full-text form by two other independent reviewers. Conflicts were resolved in a meeting of all four reviewers. Full-text papers were included in this review only if consensus was achieved between reviewers.

\section{Results}

Scoping review descriptive statistics

Of the 212 abstracts and titles screened for relevance, 15 were considered relevant primary research, and included in the study.

\section{Space for Figure 1}

Literature on OF concentrated on the clinical management of the condition. A number of articles were also found on the social and economic impact of OF on the lives of the women. As shown in Fig 1, the majority of the articles included were published in 2015. None of the studies reviewed were published in 2009. This review only included articles that were peer-reviewed. All articles included, except one, were conducted in Africa.

\section{Space for Figure 2}

The article distribution was as follows: Medline 39, PubMed 82, CINAHL 83, Thesis 7 and grey literature 1. Twenty-six were duplicates. Thirteen abstracts were validated and identified as relevant in addressing issues of post OF repair in women.

Table 1 below shows that most studies reviewed used the qualitative approach.

\section{Table 1: General characteristics of primary research publications}

Overview

The studies reviewed addressed several aspects of women's experiences of OF. Some articles focussed on self-support $[10,11]$ where women became resilient and acquired skills for survival. Most studies reported that women who had successful OF repairs became advocates for other women suffering from the same condition $[10,12-14]$. Studies reviewed also identified types of support required by women who 
had undergone successful fistula repair. The women needed emotional support, financial support, educational support, information support, religious support, and support from family members.

There were variations in the data collection methods used in the studies reviewed. One study used both interviews and questionnaire; three studies used pre-validated standard survey questionnaires. Six studies used interviews only. Three studies used interviews and observation, and one study used survey and interviews.

Social support

Although support was described as tangible, such as provision of basic needs, many women were of the view that this did not suffice in addressing emotional and social needs [10]. In some studies social support entailed assisting the women with household chores, and social interaction $[15,16]$. Support is also conceptualised in structural terms (e.g. being part of a social network) [17].

\section{Berkman's Model}

We used the Berkman's model to guide our analysis of studies on the experience of social support by women after surgical repair. Berkman's Model suggests that there is a link between social resources, support, and disease risk [18]. A study conducted in Kenya on the lived experience of women before and after OF repair found that surgical repair and physical recovery did not automatically result in psychological well-being [11]. Using Berkman's (2000) model (Fig 1) support for women with OF was classified as either internal (self-support) or external. After suffering from OF, women developed resilience and a strong will to survive OF. They also developed a desire to support other women in similar circumstances.

\section{Space for Figure 3}

Internal support

Self-efficacy

Many women in the studies reviewed reported loss of support from someone close to them after they developed OF $[10,11,15,19,20]$. Due to stigma experienced, affected women had poor role identity and isolated themselves from social participation [11]. Some women were considered to have brought shame on their families because of the fistula, and, as a result, were forced to move out of the community [20]. As such the women became resilient and believed they could save themselves [10].

Women who had suffered abuse from their husbands were reluctant to consider re-marriage and if not divorced, to get pregnant again $[11,21]$. Similarly, other women were reticent to form close bonds after being abandoned by close friends.

The major form of support reported in the studies was spousal support. The majority of women had separated from their spouses because of the OF. Many women were afraid that their husbands would not 
support them if they remained married to them. Berkman et al [22] argues that ongoing participation in social networks support the development of self-esteem. However, Berkman et al also acknowledges that not all social ties are supportive. This resonates with the experiences of women in some of the studies reviewed who were not supported by their husbands.

After OF surgical repair some women were not able to bear children. In cultures where the women's role is to bear children and perform household chores, these women felt they had lost their personal identities [23].

Internal locus of control

Experiencing OF assisted some women to change their perspective on life. In the review four studies identified development or strengthening of internal locus of control as a positive outcome of suffering from OF. Some described themselves to have become stronger and more inner oriented than before [23]. Another study found that most women did not want to seek support from non-governmental organisations, instead they believed they would make it on their own [19]. Further, women who believed would make it on their own also desired to marry again and have children. Other studies demonstrated that women used religion to build their internal locus of control. A study done in Tanzania reported that religious institutions were important both as social structures and sources of influence on people's behaviours and beliefs [24]. One of the studies reviewed had found that women with higher levels of support exhibited higher levels of self-esteem [15].

Although women experienced reduction in stigma after OF repair, some continued to exhibit negative selfperception [25]. The negative self-perception was found to be highly correlated with lack of social support [15]. For some women negative self-perception was as a result of residual distress and anxiety [13].

\section{External support}

Support from other people was therapeutic for women recovering from OF. One study conducted in Tanzania specifically reported that women with fistula had significantly less social support as compared to other gynaecologic patients [26]. However, other studies reported that women were supported by their husbands, family, and church $[15,19,21]$. One important area of support women required after OF surgical repair was with their husbands to abstain from sex [15]. The mere feeling of being accepted back in society where people depend on each other was emotionally and psychologically therapeutic for many women $[20,27]$. Women recovering from OF also valued home visits as these were a source of encouragement [14].

Since OF mostly affects people of low socio-economic status, most surgical repair services are free, therefore, most women find it difficult to request extra support after repair [28]. Maulet et al.'s study found that treatment of OF was only focused on surgery and ignored psychosocial support. Women in the study reported that psychosocial support was only provided by non-governmental staff and other patients. 
One study reported traditional values where being divorced was considered a stain on the woman's clan [20]. As such women divorced because of OF were often not accepted back into their family and clan, whereas other families accepted women suffering from OF. In such circumstances, women relied on their families because culturally family member have unbreakable ties [10].

Being accepted back into their communities was a psychological boost for women after surgical repair $[10,20]$. However, for the family accepting a woman recovering from OF repair has implications, in most African societies women are responsible for most chores which are taken up by other family members or husbands [16].

Another study described angry women who felt unsupported to make right choices in their childhood [23]. These women believed the fistula they suffered was due to early marriage and consummating marriage before or soon after menarche.

\section{Economic support}

OF primarily affects women of low socio-economic status $[10,16]$. Most studies reported that families pooled their resources to support women to access treatment and travel for follow-up hospital visits $[10,15,16,20]$. Women experienced a sense of failure when they relied on their parents and siblings for financial support [13]. Obstetric Fistula caused women to be unable to engage in productive work. After recovery many women took a long time to regain their economic independence [19]. As a result some women desired to be supported through education [20]. Some more studies identified initiatives that supported women to attain economic independence by providing skills training such as embroidery, soap making, and tie dyeing $[19,20]$. However, evidence in these studies suggest that women did not find these initiatives suitable for their economic circumstances $[19,20]$.

\section{Educational support}

Some women in the studies reviewed grew up in families that discouraged girls from going to school and prepared them for marriage [23], as such they blamed the practice of discouraging girls from getting educated and preparing them for marriage at an early age. Women dropped out of school because of early marriages or pregnancies $[14,20,23]$.

Berkman et al [22] observe that one of the least researched areas is the role of social networks in promoting health and access to life opportunities. To pursue life opportunities women desired to go back to school or be trained in some skill that would bring them livelihood. Educational support gave the women confidence in future achievements [14]. However, some of the skills training programmes offered to women after OF repair were irrelevant to their circumstances or were not profitable in their villages [20].

Support with information about obstetric fistula

Of the studies that reported the need among women for OF information, only one [14] indicated that women had fair knowledge about the condition. Most studies reported that women were either not able to 
access information or ashamed to ask questions $[10,21]$. Women were only comfortable to ask questions after successful surgical repair. For some women, accessing information was a challenge due to language [13] or cultural barriers [10]. As a result most women thought they were the only ones suffering from OF. In some cases, women and their families believed that the OF was as a result of being bewitched [10]

Some health workers were not trained in OF, as a result they were poorly informed about OF [10]. Staff in the fistula center were also poorly informed about schedules for surgeries. As a result staff were not able to guide patients and guardians properly. This resonates with findings reported in Donnelly et al.'s study where women faced language barrier in their post-repair counselling and were not able to ask questions [13].

\section{Supporting others}

Women in studies reviewed were engaged is advocacy to support other women. They supported others by creating awareness about OF. Women flagged the importance of women given skills and knowledge on how to access health care and navigate their way through the health system $[12,13,23]$. In a study Drew et al. [14] asked Malawian women to suggest the forms of support that would be beneficial to other women with OF. The women suggested that women with OF should be supported to come out and speak up about their condition and access to OF repair.

Women who successfully integrated back into their communities were highly motivated to support other women suffering from OF [12-14]. In Drew et al.'s study almost half the women knew other women suffering from OF and were willing to support them [14]. Similarly, women in Donnelly et al.'s study expressed willingness to participate in OF advocacy and assist other women get fistula repair [13].

Access to resources and material goods

As stated earlier, OF disproportionately affects women in developing countries. OF caused women not to work due to stigma [11] and loss of economic autonomy [12]. In addition, OF brought about illness related expenses such as transport to the hospital, and for hygiene products. Women relied on family, relatives, and friends for support $[15,16]$. Some families were critical of initiatives that provided financial and material support to women only. They believed support should benefit the whole family since they are all affected [16].

Material support was a community practice. Women reported that when returning to their village family and friends welcomed them with songs, gifts and food [15]. To assist women reintegrate into the community after repair relatives bought soap, lotion, and clothes to ensure that they were able to maintain hygiene [21]. Some women disliked the dependence on others for material support, and wished to have a home and economic independence [13]. Support with material goods was important for women and their families because some sold household items to pay for illness related expenses [23]. 


\section{Discussion}

The studies reviewed suggest that OF management is pre-occupied with surgery processes and ignores the psychosocial needs of patients and survivors. Women are considered completely healed after successful surgical repair. As such they were expected to resume their normal lives as before. This review demonstrated that physical healing after surgical repair did not automatically result into emotional and psychological recovery, hence reintegration of women into their communities after repair needs to focus on their well-being beyond physical recovery.

Social influence

As depicted in Berkman's model of social integration, social support is one of the major pathways through which social networks influence physical and mental health [22]. As argued by Berkman, social support is not the only critical pathway that influences health. Social networks can also be detrimental to health $[15,20]$. Rook found that women who experienced detrimental effects of social support characterised their social relations as unequal in terms of decision making. Specifically, they were more likely to say friends decided rather than they themselves or mutually to engage in a particular activity [29]. This flags the need for social support services to empower women to make independent decisions about marriage, pregnancy, and education.

This review has demonstrated that some women were at risk for OF because they lacked support to make informed decisions early in life. As a result, some dropped from school and engaged in early marriages [23]. This augurs with Berkman, Kawachi, and Glymour [22] who suggest that social factors influence diseases by creating susceptibility and vulnerability [18].

Women suffering from OF were also influenced by their social relations to seek or not seek help. Family and church members, and communities put resources together to enable women suffering from OF to access fistula repair services [15]. A woman in Dennis et al.'s [15] study described how her husband called a doctor to arrange for her surgical repair. Some women received money, food and accommodation from their religious congregations [13]. Women who were not supported by husbands, co-wives, in-laws and community members hid their illness to protect themselves from stigma, gossip and ridicule. Social support for women suffering or recovering from OF often start within marriage. Marriage is a social institution that, if stable, provides a protective shell in times of need [22].

Most women expressed unwillingness to marry again or have friends after being abused by their husbands and abandoned by close friends. Cohen [8] observes that receiving support from network members without requesting it reinforces self-esteem, intimacy, and dependability in the relationship. 
All studies reviewed suggest that social support is an important determinant of physical and psychological well-being of women after surgical repair. However, Uchino [30] observes that the conceptual basis of the link between social support and health is not fully understood. It is therefore imperative to understand this link so that when supporting women before and after OF appropriate support is given.

Support from others

Studies reviewed indicated that some women sought medical help late. There were also women who knew other women who were suffering from OF without seeking medical help. This review has shown that one of the enablers for health seeking among OF patients is social support. It has also demonstrated that social support is critical for women to achieve total recovery (physical and psychological). However, Rook's study [29] found that it is not the number of social interactions that had positive influence of psychological well-being but the number of people women were comfortable with. As identified in this review some social interactions were toxic. Women were stigmatised because of OF and after repair they had to return to that environment [20]. Additionally, many women were rejected by their husbands and had no home to return to $[10,11,20]$.

Access to resources and material goods

Most women in countries where OF is common live in poverty. As such they lack resources and materials for everyday survival. Social networks work to facilitate individual's access to resources within the network or in other overlapping networks [22]. Hyyppä [31] observes that individual level social capital enable individuals access resources that contribute to health. Hyyppä identifies networks such as friendship networks (reciprocal trust) and hobby groups. Women in the studies reviewed accessed resources from family members, religious organisations, and non-governmental organisations implementing interventions on OF to travel to fistula treatment centres. Therefore, social networks work to provide resources that result in better health or better care for network members [8]. As identified in this review, Smith and Christakis [32] observes that people tend to form social networks with similar others. The similarity could be age, income or health status. However, people of low socio-economic status tend to have smaller networks and as a result access fewer resources. This resonates with the situation of women suffering from OF who are mostly from low socio-economic statuses. This flags up the need for deliberate programmes to create networks for women who have recovered from OF and those suffering from OF.

\section{Conclusions}

Our study is a review of existing studies on social support for women recovering from OF and reintegrating back in their communities. Our study shows that there are few studies conducted in this area. Most studies on OF were on clinical management of the condition. However, our study has found that social networks make an important contribution to the recovery of women after OF repair. As such, 
ignoring the psychological needs of the women after surgical repair results in difficulties in re-integration into homes and community.

All studies reviewed suggest that social support contributes to physical and psychological well-being. The women's bodies were weak after surgical repair and needed to be supported with carrying out household chores. The studies reviewed identified support as being internal and external. The experience of OF and abandonment made women strong and resilient. They believed that they could save themselves from OF. Although OF is one of the major birth complications, there is lack of studies on social support for women suffering from the condition. We observe that such studies would inform design of treatment programmes that are holistic.

\section{Abbreviations}

CINAHL: Cumulative Index of Nursing and Allied Health

OF: Obstetric Fistula

UNFPA: United Nations Population Fund

WHO: World Health Organisation

\section{Declarations}

\section{Ethics approval and consent to participate}

Not applicable

\section{Consent for publication}

Not applicable

\section{Availability of data and material}

The studies used in this review are included in the reference list

\section{Competing interests}

The authors declare that they have no competing interests

\section{Funding}

Not applicable

\section{Authors' contributions}


$\mathrm{KW}$ performed the literature search. All authors screened the literature for relevance and extracted the data. KW analyzed the data and drafted the manuscript in collaboration with EC. EC was the subject specialist, responsible for the technical consistency of the manuscript. EC, AN, and BC revised the manuscript and edited the English language. All authors read and approved the final manuscript.

\section{Acknowledgements}

The authors thank Professor Pammla Petrucka (University of Saskatchewan, Canada) for her valuable guidance and mentorship in the process of conducting scoping reviews.

\section{References}

1. Letchworth P, MacLaren E, Duffy S. Obstetric fistula: a paradigm shift is needed in research and prevention. BJOG An Int J Obstet Gynaecol [Internet]. 2018 Jul 1 [cited 2019 Mar 9];125(8):925-8. Available from: http://doi.wiley.com/10.1111/1471-0528.15110

2. World Health Organisation. 10 facts on obstetric fistula [Internet]. 2014 [cited 2019 Mar 9]. Available from: http://www.who.int/features/factfiles/obstetric_fistula/en/

3. Tunçalp Ö, Tripathi V, Landry E, Stanton CK, Ahmed S. Measuring the incidence and prevalence of obstetric fistula: approaches, needs and recommendations. Bull World Health Organ [Internet]. 2015 Jan 1 [cited 2019 Mar 9];93(1):60-2. Available from: http://www.who.int/entity/bulletin/volumes/93/1/14-141473.pdf

4. Kalilani-Phiri L V., Umar E, Lazaro D, Lunguzi J, Chilungo A. Prevalence of obstetric fistula in Malawi. Int J Gynecol Obstet [Internet]. 2010 Jun [cited 2019 Mar 7];109(3):204-8. Available from: http://www.ncbi.nlm.nih.gov/pubmed/20219194

5. United Nations Population Fund. Obstetric fistula [Internet]. 2018 [cited 2018 Nov 26]. Available from: https://www.unfpa.org/obstetric-fistula

6. Shorey S, Chan SWC, Chong YS, He H-G. A randomized controlled trial of the effectiveness of a postnatal psychoeducation programme on self-efficacy, social support and postnatal depression among primiparas. J Adv Nurs [Internet]. 2015 Jun [cited 2019 Mar 7];71(6):1260-73. Available from: http://www.ncbi.nlm.nih.gov/pubmed/25496615

7. Finfgeld-Connett D. Clarification of Social Support. J Nurs Scholarsh [Internet]. 2005 Mar 1 [cited 2019 Mar 7];37(1):4-9. Available from: http://doi.wiley.com/10.1111/j.1547-5069.2005.00004.x

8. Cohen S. Social relationships and health. Am Psychol. 2004;59(8):676.

9. Khan RL, Antonucci TC. Convoys over the life course: attachment, roles and social support. In: Baltes P, Brim O, editors. Life span development and behavior. San Diego CA: Academic Press; 1980. p. 253-86.

10. Sullivan G, O'Brien B, Mwini-Nyaledzigbor P. Sources of support for women experiencing obstetric fistula in northern Ghana: A focused ethnography. Midwifery [Internet]. 2016 Sep 1 [cited 2018 Nov 
21];40:162-8. Available from:

https://www.sciencedirect.com/science/article/pii/S0266613816301164

11. Khisa W, Wakasiaka S, McGowan L, Campbell M, Lavender T. Understanding the lived experience of women before and after fistula repair: a qualitative study in Kenya. BJOG An Int J Obstet Gynaecol [Internet]. 2017 Feb 1 [cited 2018 Nov 21];124(3):503-10. Available from: http://doi.wiley.com/10.1111/1471-0528.13902

12. Désalliers J, Paré M-E, Kouraogo S, Corcos J. Impact of surgery on quality of life of women with obstetrical fistula: a qualitative study in Burkina Faso. Int Urogynecol J [Internet]. $2017 \mathrm{Jul} 26$ [cited 2018 Nov 21];28(7):1091-100. Available from: http://link.springer.com/10.1007/s00192-016-3235-x

13. Donnelly K, Oliveras E, Tilahun Y, Belachew M, Asnake M. Quality of life of Ethiopian women after fistula repair: implications on rehabilitation and social reintegration policy and programming. Cult Health Sex [Internet]. 2015 Feb 7 [cited 2018 Nov 21];17(2):150-64. Available from: http://www.tandfonline.com/doi/abs/10.1080/13691058.2014.964320

14. Drew LB, Wilkinson JP, Nundwe W, Moyo M, Mataya R, Mwale M, et al. Long-term outcomes for women after obstetric fistula repair in Lilongwe, Malawi: a qualitative study. BMC Pregnancy Childbirth [Internet]. 2016 Dec 5 [cited 2018 Nov 21];16(1):2. Available from: http://www.biomedcentral.com/1471-2393/16/2

15. Dennis AC, Wilson SM, Mosha M V, Masenga GG, Sikkema KJ, Terroso KE, et al. Experiences of social support among women presenting for obstetric fistula repair surgery in Tanzania. Int J Womens Health [Internet]. 2016 [cited 2018 Nov 22];8:429-39. Available from: http://www.ncbi.nlm.nih.gov/pubmed/27660492

16. Jarvis K, Richter S, Vallianatos H, Thornton L. Reintegration of women post obstetric fistula repair: experience of family caregivers. Glob Qual Nurs Res [Internet]. 2017 Dec 7 [cited 2018 Nov 22];4:233339361771492. Available from: http://journals.sagepub.com/doi/10.1177/2333393617714927

17. Reblin M, Uchino BN. Social and emotional support and its implication for health. Curr Opin Psychiatry [Internet]. 2008 Mar [cited 2018 Dec 18];21(2):201-5. Available from: https://insights.ovid.com/crossref?an=00001504-200803000-00021

18. Berkman LF, Kawachi I, editors. Social epidemiology. Oxford University Press; 2000.

19. Teddy Mselle L, Evjen-Olsen B, Marie Moland K, Mvungi A, Wankuru Kohi T. Hoping for a normal life again: reintegration after fistula repair in Rural Tanzania. J Obstet Gynaecol Canada. 2012;34(10):927-38.

20. Jarvis K, Richter S, Vallianatos H. Exploring the needs and challenges of women reintegrating after obstetric fistula repair in northern Ghana. Midwifery. 2017;50:55-61.

21. Pope $\mathrm{R}$, Bangser $\mathrm{M}$, Requejo JH. Restoring dignity: Social reintegration after obstetric fistula repair in Ukerewe, Tanzania. Glob Public Health. 2011;6(8):859-73.

22. Berkman LF, Glass T, Brissette I, Seeman TE. From social integration to health: Durkheim in the new millennium. Soc Sci Med [Internet]. 2000 Sep [cited 2018 Dec 11];51(6):843-57. Available from: 
http://www.ncbi.nlm.nih.gov/pubmed/10972429

23. Gebresilase YT. A qualitative study of the experience of obstetric fistula survivors in Addis Ababa, Ethiopia. Int J Womens Health [Internet]. 2014 [cited 2018 Nov 22];6:1033-43. Available from: http://www.ncbi.nlm.nih.gov/pubmed/25525395

24. Watt MH, Wilson SM, Joseph M, Masenga G, MacFarlane JC, Oneko O, et al. Religious coping among women with obstetric fistula in Tanzania. Glob Public Health [Internet]. 2014 May 28 [cited 2018 Dec 13];9(5):516-27. Available from:

http://www.tandfonline.com/doi/abs/10.1080/17441692.2014.903988

25. El Ayadi AM, Barageine J, Korn A, Kakaire O, Turan J, Obore S, et al. Trajectories of women's physical and psychosocial health following obstetric fistula repair in Uganda: a longitudinal study. Trop Med Int Heal [Internet]. 2019 Jan 1 [cited 2019 May 16];24(1):53-64. Available from: http://doi.wiley.com/10.1111/tmi.13178

26. Wilson SM, Sikkema KJ, Watt MH, Masenga GG. Psychological symptoms among obstetric fistula patients compared to gynecology outpatients in Tanzania. Int J Behav Med [Internet]. 2015 Oct 11 [cited 2018 Nov 23];22(5):605-13. Available from: http://link.springer.com/10.1007/s12529-0159466-2

27. Young-Lin N, N. Namugunga EN, Lussy JP, Benfield N. Healthcare providers' perspectives on the social reintegration of patients after surgical fistula repair in the eastern Democratic Republic of Congo. Int J Gynecol Obstet. 2015;130(2015):161-164.

28. Maulet N, Berthe A, Traore S, Macq J. Obstetric fistula "disease" and ensuing care: patients' views in West-Africa. Afr J Reprod Health. 2015;19(1):112-23.

29. Rook KS. The negative side of social interaction: Impact on psychological well-being. J Pers Soc Psychol [Internet]. 1984 [cited 2018 Dec 13];46(5):1097-108. Available from: http://doi.apa.org/getdoi.cfm?doi=10.1037/0022-3514.46.5.1097

30. Uchino BN. Understanding the links between social support and physical health: a life-span perspective with emphasis on the separability of perceived and received support. Perspect Psychol Sci [Internet]. 2009 May 1 [cited 2018 Dec 18];4(3):236-55. Available from: http://journals.sagepub.com/doi/10.1111/j.1745-6924.2009.01122.x

31. Hyyppä MT. Healthy ties: social capital, population health and survival. London: Springer; 2010.

32. Smith KP, Christakis NA. Social networks and health. Annu Rev Sociol [Internet]. 2008 Aug 7 [cited 2019 Mar 8];34(1):405-29. Available from:

http://www.annualreviews.org/doi/10.1146/annurev.soc.34.040507.134601

\section{Tables}

$\underline{\text { Table } 1}$

Page 15/18 


\begin{tabular}{|c|c|c|}
\hline Category & & Count \\
\hline \multicolumn{3}{|c|}{ Type of citation } \\
\hline & Primary peer-reviewed & 15 \\
\hline \multicolumn{3}{|l|}{ Language } \\
\hline & English & 15 \\
\hline \multicolumn{3}{|l|}{ Continent } \\
\hline \multicolumn{3}{|c|}{ Africa } \\
\hline & Burkina Faso & 1 \\
\hline & Ethiopia & 2 \\
\hline & Ghana & 3 \\
\hline & Kenya & 1 \\
\hline & Malawi & 1 \\
\hline & Tanzania & 5 \\
\hline & Uganda & 1 \\
\hline \multicolumn{3}{|c|}{ Asia } \\
\hline & Bangladesh & 1 \\
\hline \multicolumn{3}{|c|}{ Study design } \\
\hline & Mixed methods & 4 \\
\hline & Ethnography & 3 \\
\hline & Cross-sectional study & 1 \\
\hline & Grounded theory & 1 \\
\hline & Phenomenology & 1 \\
\hline & Survey & 1 \\
\hline & Longitudinal cohort study & 1 \\
\hline & Not stated & 3 \\
\hline
\end{tabular}

Figures 


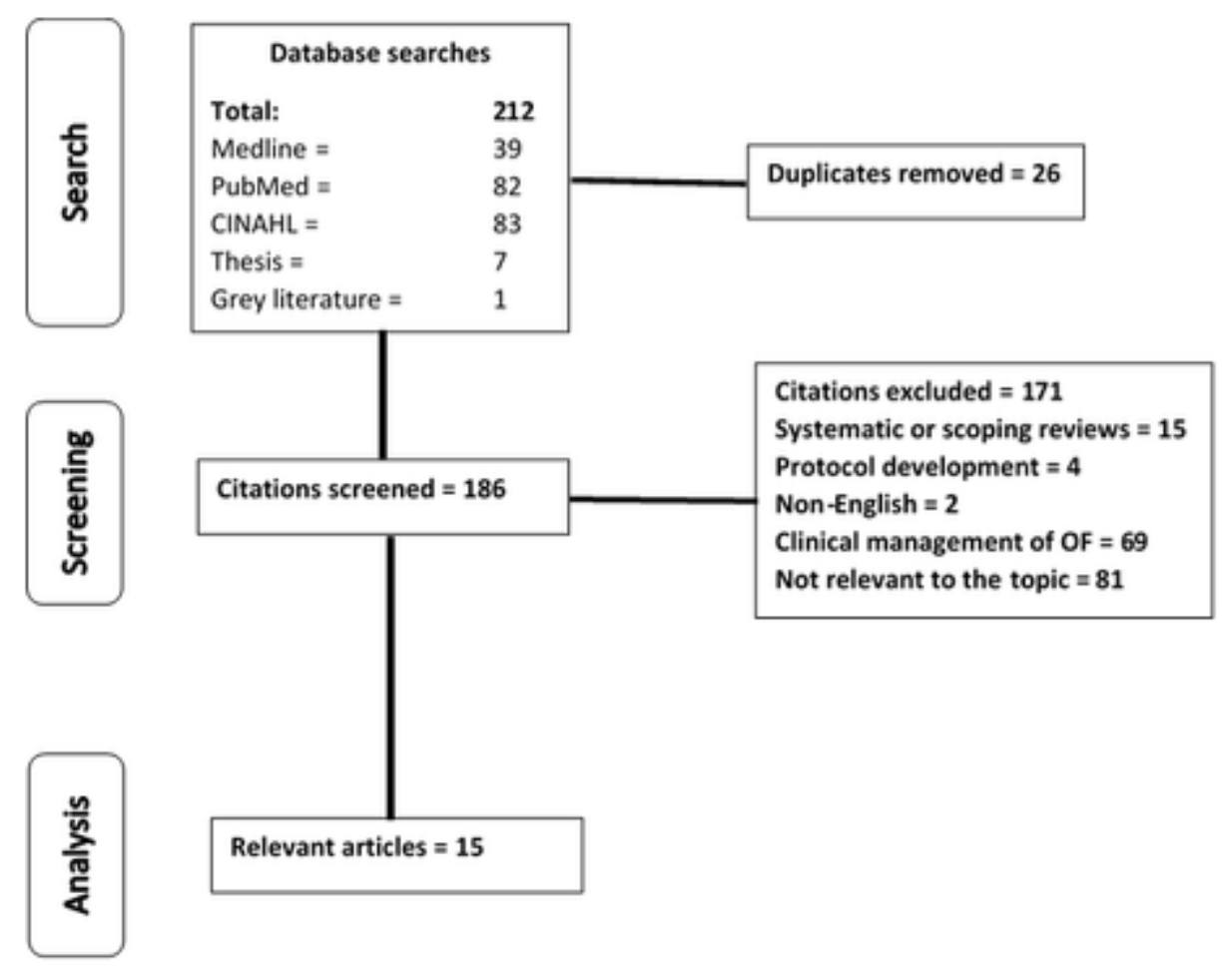

Figure 1

Flow of citation through the review process

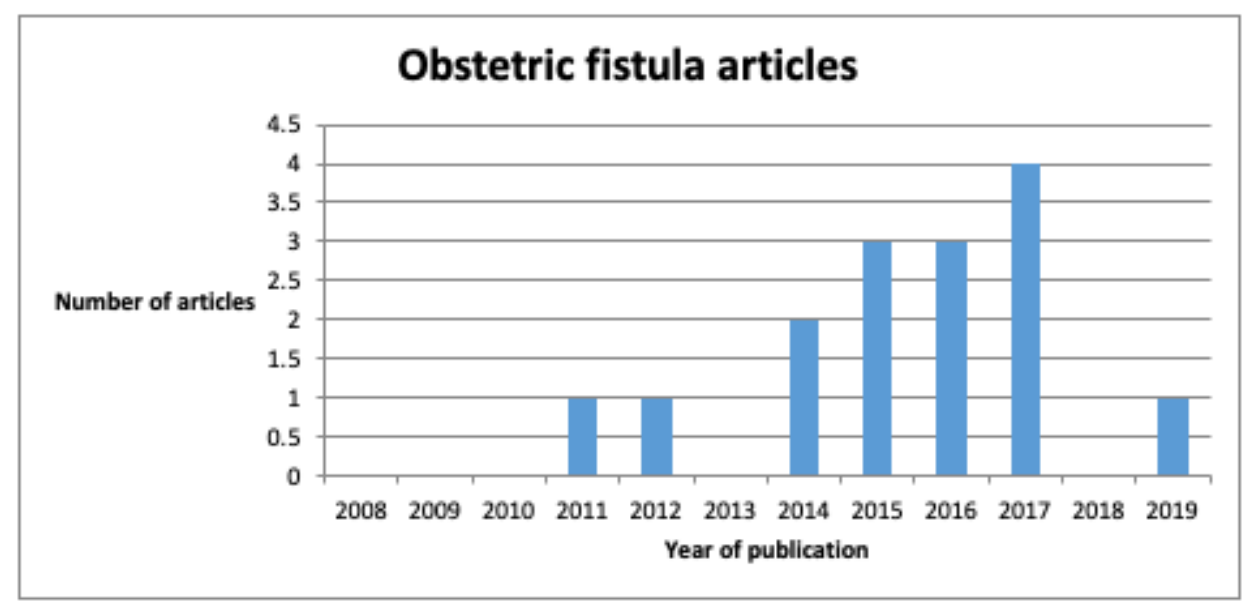

Figure 2

Number of publications on obstetric fistula 


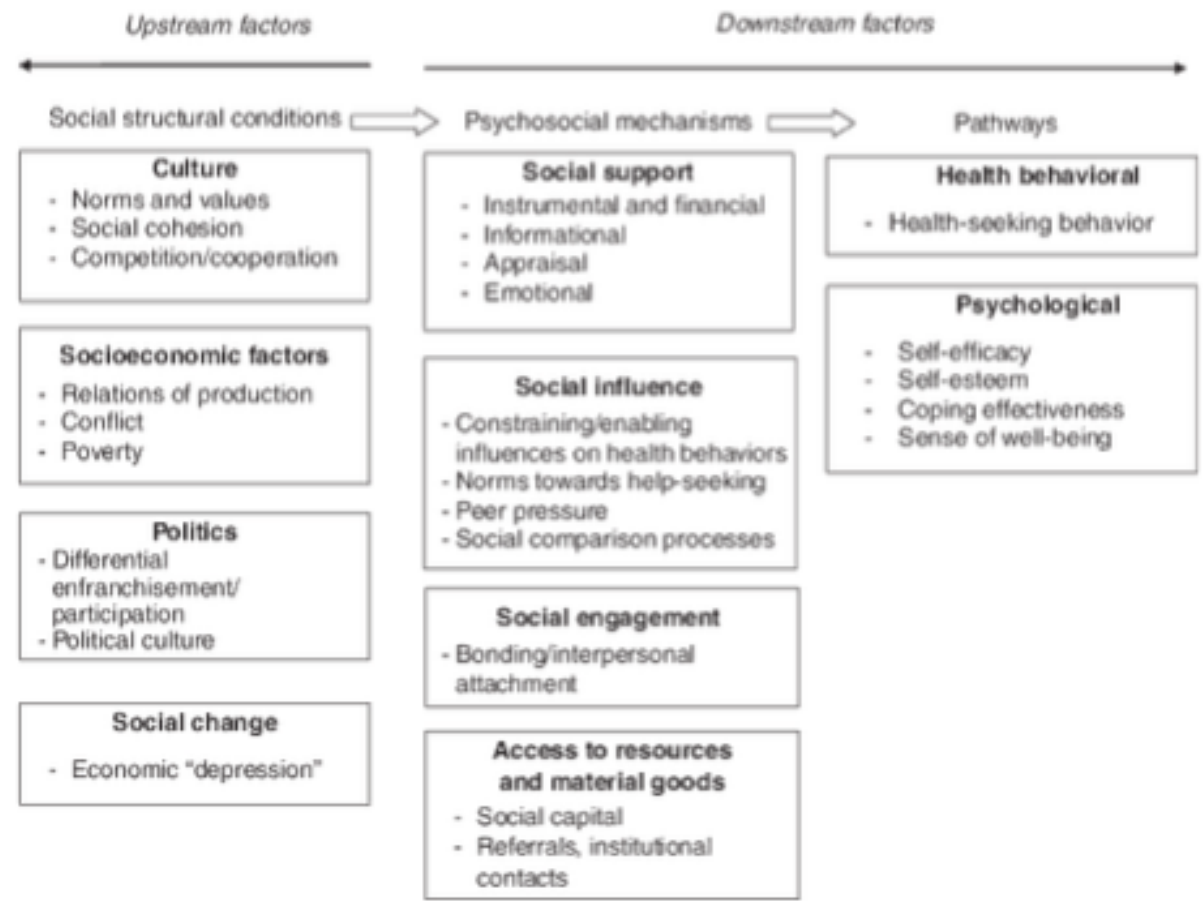

\section{Figure 3}

Model proposed by Berkman et al. (2000)

\section{Supplementary Files}

This is a list of supplementary files associated with this preprint. Click to download.

- Appendix1.docx 